\title{
The chemistry of daytime sprite streamers - a model study
}

\author{
H. Winkler and J. Notholt \\ Institut für Umweltphysik, Universität Bremen, Bremen, Germany \\ Correspondence to: H. Winkler (hwinkler@iup.physik.uni-bremen.de) \\ Received: 23 September 2013 - Published in Atmos. Chem. Phys. Discuss.: 12 November 2013 \\ Revised: 4 February 2014 - Accepted: 14 February 2014 - Published: 8 April 2014
}

\begin{abstract}
The chemical processes in daytime sprite streamers in the altitude range of $30-54 \mathrm{~km}$ are investigated by means of a detailed ion-neutral chemistry model (without consideration of transport). The focus lies on nitrogen, hydrogen and oxygen species, and in particular on ozone perturbations. Initial effects of the breakdown electric fields at the tip of sprite streamers include a short-term loss of ozone due to ion-chemical reactions, a production of nitrogen radicals, and a liberation of atomic oxygen. The latter leads to a formation of ozone. In terms of relative ozone change, this effect decreases with altitude. The model results indicate that the subsequent ozone perturbations due to daytime sprites streamers differ considerably from the ones of night-time events. For night-time conditions, reactive nitrogen produced at the streamer heads is rapidly converted into significantly less reactive $\mathrm{NO}_{2}$, and there is basically no ozone depletion. The situation is different for daytime conditions where $\mathrm{NO}_{\mathrm{x}}$ causes catalytic ozone destruction. As a consequence, there is significant ozone loss in sprite streamers in the daytime atmosphere, in particular at higher altitudes. At an altitude of $54 \mathrm{~km}$, ozone in the streamer column has decreased by about $15 \%$ fifteen minutes after the sprite event.
\end{abstract}

\section{Introduction}

Sprites are transient luminous discharges in the mesosphere occurring above active thunderstorms. Since Franz et al. (1990) reported on the detection of such an event, numerous sprite observations have been made from aircraft (Sentman et al., 1995), from space (e.g. Boeck et al., 1995; Chen et al., 2008), and by ground-based instruments (see Neubert et al., 2008, and references therein). Almost all sprites are associated with positive cloud-to-ground (+CG) lightning discharges (Boccippio et al., 1995), and it is well established that sprites are triggered by the underlying lightning. The initiation of sprites can be explained by conventional air breakdown at mesospheric altitudes caused by lightning-driven electric fields, for example, Pasko et al. (1995); Cho and Rycroft (1998).

There are different types of sprites, and they can be classified based on shape, size, and structure, (e.g. Bór, 2013). Generally, sprites consist of three regions. There is a diffuse upper part (sprite halo), a bright transition region, and a lower streamer region, (Pasko et al., 1998; Pasko and StenbaekNielsen, 2002). However, halo and streamers are not observed in all sprite events. Their development depends on the parameters of the parent lightning events, (Adachi et al., 2008). Streamers are self-sustaining plasma filaments. Once formed, they can propagate through an under-voltage regime, that is, regions where the ambient electric field is significantly smaller than the breakdown electric field. Typically, sprite streamers are initiated at altitudes $\sim 70-85 \mathrm{~km}$, and propagate downwards for several kilometres (Moudry et al., 2003; Cummer et al., 2006; McHarg et al., 2007). Upward propagating streamers, when present, develop later and from lower altitudes, (Cummer et al., 2006; Stenbaek-Nielsen and McHarg, 2008).

During the day, the ionospheric conductivity is significantly higher than at night and conventional breakdown is prevented at mesospheric altitudes. Therefore, daytime sprites have to be initiated at lower altitudes. Due to the higher atmospheric density, larger electric fields are required to cause air breakdown. As a result, only exceptionally large lighting events can trigger daytime sprites (Stanley et al., 2000). Additionally, sprites occurring in the sunlit atmosphere might be difficult to observe by optical devices. To the best knowledge of the authors, there are only three published reports on daytime sprites. All of them have been detected by non-optical methods: Stanley et al. (2000) have discovered 
three daytime sprites by their signatures in the electromagnetic extremely low frequency band. Farges et al. (2005) have detected infrasound signals of three daytime sprites. Kumar et al. (2008) measured electromagnetic perturbations in the very low frequency regime during day, and tentatively related them to sprite or ELVES (Emission of Light and Very Low Frequency perturbations from Electromagnetic Pulse Sources) events. All of these events occurred within a few hours after sunrise, or a few hours before sunset.

It is well established that atmospheric discharges have chemical effects. In particular there is a formation of reactive nitrogen species, and a liberation of atomic oxygen. Both of which eventually affect the ozone chemistry, (Borisov et al., 1993). Tropospheric lightning is a well-known source of reactive nitrogen, (Price et al., 1997), and in recent years the chemical impacts of sprites gained some interest. There have been attempts to find sprite induced enhancements of nitrogen species in the middle atmosphere by exploiting satellite data (Rodger et al., 2008; Arnone et al., 2009). On the other hand, a number of model studies on the chemical impacts of sprites have been presented, for example, Sentman et al. (2008a); Gordillo-Vázquez (2008); Hiraki et al. (2008); Enell et al. (2008).

To the best knowledge of the authors, until now there are only two publications touching the chemistry of daytime sprites. Hiraki et al. (2004) have modelled the production of $\mathrm{O}\left({ }^{1} \mathrm{D}\right)$ in night-time and daytime sprite halos, and Evtushenko and Mareev (2011) have simulated sprite events for night-time as well as daytime conditions. Both of these studies dealt with the diffuse region of sprites but not with streamers which are thought to significantly contribute to the chemical impact of sprites.

The present work is devoted to the investigation of chemical effects in the streamer zone of a daytime sprite. For this purpose, an ion-neutral chemistry model has been set up. In order to realistically simulate daytime conditions, the model includes photoreactions of charged and neutral species. The model is applied to atmospheric conditions similar to the daytime sprites detected by Stanley et al. (2000).

\section{Sprite chemistry}

The electric fields in sprites drive electron impact ionisation, dissociation and excitation of air molecules and atoms. Due to the large abundance of $\mathrm{N}_{2}$ and $\mathrm{O}_{2}$, the main ionisation processes are

$$
\begin{aligned}
\mathrm{N}_{2}+\mathrm{e} & \rightarrow \mathrm{N}_{2}^{+}+2 \mathrm{e} \\
& \rightarrow \mathrm{N}^{+}+\mathrm{N}+2 \mathrm{e}, \\
\mathrm{O}_{2}+\mathrm{e} & \rightarrow \mathrm{O}_{2}^{+}+2 \mathrm{e} \\
& \rightarrow \mathrm{O}^{+}+\mathrm{O}+2 \mathrm{e}
\end{aligned}
$$

where the reaction products can be in their ground states or in excited states. Free atoms in ground state and excited states result also from dissociative electron impact:

$\mathrm{N}_{2}+\mathrm{e} \rightarrow \mathrm{N}+\mathrm{N}+\mathrm{e}$,

$\mathrm{O}_{2}+\mathrm{e} \rightarrow \mathrm{O}+\mathrm{O}+\mathrm{e}$.

Additionally, collisions of electrons with $\mathrm{N}_{2}$, and $\mathrm{O}_{2}$ produce electronically excited molecules and/or excited molecules through vibration. Furthermore, electric fields facilitate electron attachment. Of particular importance is the reaction

$\mathrm{O}_{2}+\mathrm{e} \rightarrow \mathrm{O}^{-}+\mathrm{O}$.

The released reactive species initiate rapid ion-neutral reactions. Due to the complexity of air plasma reactions, detailed models are required to assess the subsequent chemical effects of discharges in air (Kossyi et al., 1992). The chemistry of sprites has been simulated in some detail. Sentman et al. (2008a) used an elaborate plasma chemistry model of more than 80 positive, negative and uncharged species to investigate the impact of a single sprite streamer at $70 \mathrm{~km}$. Later, Sentman and Stenbaek-Nielsen (2009) expanded the model by considering the weak electric fields in the trailing column of the sprite streamer. Gordillo-Vázquez (2008) used a full-time-dependent kinetic model of more than 75 ions and neutral species to simulate in detail the effect of a sprite streamer at three different altitudes in the upper mesosphere. Hiraki et al. (2008) modelled the impact of a sprite streamer on the positive ion chemistry in the mesosphere. Enell et al. (2008) have studied chemical effects of sprites on neutral compounds, considering both positive and negative ion reactions.

All of the model studies just mentioned were carried out for night-time conditions. For the intended simulation of daytime sprite streamers, the photoreactions of ions and neutral species have to be taken into account.

\section{Model description}

An atmospheric ion-neutral chemistry model has been set up to simulate a daytime sprite event similar to the ones reported on by Stanley et al. (2000). For night-time sprites it is known that the onset altitudes of streamers are in agreement with the calculated altitudes of conventional breakdown (e.g. Fernsler and Rowland, 1996; Hu et al., 2007; Gamerota et al., 2011). The working hypothesis here is that the same applies to the considered daytime sprite, that is, streamers are initiated at the estimated conventional breakdown altitude of $54 \mathrm{~km}$ (Stanley et al., 2000). This is motivated by the following consideration: for all three events detected by Stanley et al. (2000) there was a time lag between the triggering +CG stroke and the sprite onset of more than $10 \mathrm{~ms}$. Therefore, the dielectric relaxation time constant at $54 \mathrm{~km}$ cannot have been much smaller than $10 \mathrm{~ms}$. On the other hand, the characteristic time for the development of a streamer is of the order of $1 \mathrm{~ms}$ at $54 \mathrm{~km}$ (Pasko et al., 1998). Consequently, streamer 
formation is expected to have taken place at that altitude. The lower terminal altitude of the daytime sprites was estimated to be about $30 \mathrm{~km}$ (Stanley, 2000). Accordingly, the model is applied to the streamer zone in the altitude range $30-54 \mathrm{~km}$. The perhaps existing sprite halo is not considered.

\subsection{Streamer parametrisation}

In general, the electric field at the streamer head is significantly higher than the ambient field. As a result, the chemical perturbations in a sprite streamer zone are mainly driven by the fields at the streamer tips (e.g. Sentman et al., 2008a). The effect of the weaker electric fields in the streamer columns are modest compared to the impact at the streamer head (Sentman and Stenbaek-Nielsen, 2009). As streamer dynamics is outside the scope of this paper, the streamer parameters have to be prescribed. The electric field at a point passed by the streamer head is modelled as a boxcar field pulse of amplitude $E$. Its value is based on the scaling relation given by Raizer et al. (1998):

$E=1.5 \times 10^{5} \mathrm{~V} \mathrm{~cm}^{-1}\left(N / N_{0}\right)$,

where $N$ is the air number density at the considered height, and $N_{0}$ the corresponding value at the Earth's surface. The number density of electrons $n_{\mathrm{e}}$ produced in the streamer tip is given by (Raizer et al., 1998):

$n_{\mathrm{e}}=10^{14} \mathrm{~cm}^{-3}\left(N / N_{0}\right)^{2}$.

\subsection{Electron impact}

The model accounts for the electron impact reactions with $\mathrm{N}_{2}$ and $\mathrm{O}_{2}$ given in Table 2. The rate coefficients for the electron impact reactions can be expressed as functions of the reduced electric field $E / N$ with $E$ being the electric field strength, and $N$ the air density. The reaction coefficients have been calculated with the Boltzmann solver BOLSIG+ (Hagelaar and Pitchford, 2005). Additionally, the associative electron detachment process $\mathrm{O}^{-}+\mathrm{N}_{2} \rightarrow \mathrm{N}_{2} \mathrm{O}+\mathrm{e}$ is considered using the reaction rate coefficient as a function of $E / N$ given by Luque and Gordillo-Vázquez (2012). This approach is justified if the electron energy distribution function (EDF) is close to the steady-state EDF. Gordillo-Vázquez (2008) has demonstrated that the EDF relaxation time is indeed small compared to the typical pulse duration of a streamer tip. Therefore, using the steady-state electron impact rate coefficients for a given $E / N$ is a suitable approach to model the processes in streamers.

\subsection{Chemistry}

In order to simulate the chemical effects of sprite streamers, a model of the relevant chemical processes has been developed. The considered 91 species are given in Table 1. The change in the concentration of a species $n_{i}\left(\mathrm{~cm}^{-3}\right)$ with time is modelled as

$\frac{\mathrm{d} n_{i}}{\mathrm{~d} t}=P_{i}-l_{i} n_{i}$,

where $P_{i}\left(\mathrm{~cm}^{-3} \mathrm{~s}^{-1}\right)$ is the production rate, and $l_{i}\left(\mathrm{~s}^{-1}\right)$ is the loss rate coefficient of the $i$ th species. Concentration changes due to transport processes are not considered. This is a similar approach as taken by Sentman et al. (2008a) and GordilloVázquez (2008). It is valid for the early phase after the passage of a streamer head. Sentman et al. (2008a) estimated the characteristic timescale for diffusion in sprite streamers, and defined an upper limit of $\sim 1000 \mathrm{~s}$ for sprite streamer simulations neglecting diffusion processes. Therefore, the model results presented in this paper are limited to $15 \mathrm{~min}$ after the passage of the streamer tip. Loss and production terms have been added to the model so that a chemical steady state is achieved if no electric breakdown takes place (in order to avoid a drift of the model due to the missing atmospheric transport processes).

The Eq. (3) constitutes a system of coupled ordinary differential equations. It is solved by means of the semiimplicit symmetric method (Ramaroson, 1989; Ramaroson et al., 1992). Electrons are known to rapidly thermalise in the streamer trailing columns (Sentman et al., 2008a). Accordingly, the ambient atmospheric temperature is used as the kinetic temperature of electrons and all other species behind the streamer tip. Thermodynamic effects such as collisional, chemical or radiative heating are not considered. This is the same approach as that used by Gordillo-Vázquez (2008) and Sentman et al. (2008a).

The model accounts for electron impact processes (Table 2), photoreactions discussed below, and ion-neutral reactions listed in the supplement to this paper. Most of the reactions, and rate coefficients are taken from Kossyi et al. (1992); Kazil (2002); Gordillo-Vázquez (2008) and Sentman et al. (2008b).

The model is initialised with profiles of pressure, temperature, and trace-gas concentrations originating from a twodimensional atmospheric chemistry and transport model (Winkler et al., 2009). The atmospheric background ionisation due to galactic cosmic rays is parametrised as in Lehtinen and Inan (2007).

A few remarks are in order concerning some of the modelled species. Following Kossyi et al. (1992) it is assumed that the species $\mathrm{N}_{2} \mathrm{O}_{2}^{+}$formed in collisions of $\mathrm{O}_{2}^{+}$or $\mathrm{O}_{4}^{+}$with $\mathrm{N}_{2}$ is the cluster ion $\mathrm{O}_{2}^{+}\left(\mathrm{N}_{2}\right)$. The isomerisation barrier between $\mathrm{O}_{2}^{+}\left(\mathrm{N}_{2}\right)$ and $\mathrm{NO}^{+}(\mathrm{NO})$ is higher than the dissociation energies (Bowers et al., 1983). Therefore, it is assumed that collisional dissociation, and recombination of $\mathrm{N}_{2} \mathrm{O}_{2}^{+}$leads to $\mathrm{O}_{2}$ and $\mathrm{N}_{2}$. The species $\mathrm{H}_{2} \mathrm{O}_{2}^{-}$is assumed to be the iondipole complex $\mathrm{O}^{-}\left(\mathrm{H}_{2} \mathrm{O}\right)$ and not the slightly less stable $\mathrm{OH}^{-}(\mathrm{OH})$ (see e.g. Deyerl et al., 2001). Similarly, $\mathrm{H}_{2} \mathrm{O}_{3}^{-}$and $\mathrm{H}_{2} \mathrm{O}_{4}^{-}$are treated as $\mathrm{O}_{2}^{-}\left(\mathrm{H}_{2} \mathrm{O}\right)$ and $\mathrm{O}_{3}^{-}\left(\mathrm{H}_{2} \mathrm{O}\right)$, respectively.

The model has been tested by comparison with the welldocumented model results of Gordillo-Vázquez (2008) and 
Table 1. Modelled species.

\begin{tabular}{|c|}
\hline Negative species \\
\hline $\begin{array}{l}\mathrm{e}, \mathrm{O}^{-}, \mathrm{O}_{2}^{-}, \mathrm{O}_{3}^{-}, \mathrm{O}_{4}^{-}, \mathrm{NO}^{-}, \mathrm{NO}_{2}^{-}, \mathrm{NO}_{3}^{-}, \mathrm{CO}_{3}^{-}, \mathrm{CO}_{4}^{-}, \mathrm{O}^{-}\left(\mathrm{H}_{2} \mathrm{O}\right), \mathrm{O}_{2}^{-}\left(\mathrm{H}_{2} \mathrm{O}\right), \mathrm{O}_{3}^{-}\left(\mathrm{H}_{2} \mathrm{O}\right), \mathrm{OH}^{-}, \mathrm{HCO}_{3}^{-} \\
\mathrm{Cl}^{-}, \mathrm{ClO}^{-}, \mathrm{Cl}^{-}\left(\mathrm{H}_{2} \mathrm{O}\right), \mathrm{Cl}^{-}\left(\mathrm{CO}_{2}\right), \mathrm{Cl}^{-}(\mathrm{HCl})\end{array}$ \\
\hline Positive species \\
\hline $\begin{array}{l}\mathrm{N}^{+}, \mathrm{N}_{2}^{+}, \mathrm{N}_{3}^{+}, \mathrm{N}_{4}^{+}, \mathrm{O}^{+}, \mathrm{O}_{2}^{+}, \mathrm{O}_{4}^{+}, \mathrm{NO}^{+}, \mathrm{NO}_{2}^{+}, \mathrm{N}_{2} \mathrm{O}^{+}, \mathrm{N}_{2} \mathrm{O}_{2}^{+}, \mathrm{NO}^{+}\left(\mathrm{N}_{2}\right), \mathrm{NO}^{+}\left(\mathrm{O}_{2}\right), \mathrm{H}_{2} \mathrm{O}^{+}, \mathrm{OH}^{+}, \mathrm{H}^{+}\left(\mathrm{H}_{2} \mathrm{O}\right)_{n=1-7} \\
\mathrm{H}^{+}\left(\mathrm{H}_{2} \mathrm{O}\right)(\mathrm{OH}), \mathrm{H}^{+}\left(\mathrm{H}_{2} \mathrm{O}\right)\left(\mathrm{CO}_{2}\right), \mathrm{H}^{+}\left(\mathrm{H}_{2} \mathrm{O}\right)_{2}\left(\mathrm{CO}_{2}\right), \mathrm{H}^{+}\left(\mathrm{H}_{2} \mathrm{O}\right)\left(\mathrm{N}_{2}\right), \mathrm{H}^{+}\left(\mathrm{H}_{2} \mathrm{O}\right)_{2}\left(\mathrm{~N}_{2}\right), \mathrm{O}_{2}^{+}\left(\mathrm{H}_{2} \mathrm{O}\right), \mathrm{NO}^{+}\left(\mathrm{H}_{2} \mathrm{O}\right)_{n=1-3} \\
\mathrm{NO}^{+}\left(\mathrm{CO}_{2}\right), \mathrm{NO}^{+}\left(\mathrm{H}_{2} \mathrm{O}\right)\left(\mathrm{CO}_{2}\right), \mathrm{NO}^{+}\left(\mathrm{H}_{2} \mathrm{O}\right)_{2}\left(\mathrm{CO}_{2}\right), \mathrm{NO}^{+}\left(\mathrm{H}_{2} \mathrm{O}\right)\left(\mathrm{N}_{2}\right), \mathrm{NO}^{+}\left(\mathrm{H}_{2} \mathrm{O}\right)_{2}\left(\mathrm{~N}_{2}\right)\end{array}$ \\
\hline Neutrals \\
\hline $\begin{array}{l}\mathrm{N}, \mathrm{N}\left({ }^{2} \mathrm{D}\right), \mathrm{N}\left({ }^{2} \mathrm{P}\right), \mathrm{O}, \mathrm{O}\left({ }^{1} \mathrm{D}\right), \mathrm{O}\left({ }^{1} \mathrm{~S}\right), \mathrm{O}_{3}, \mathrm{NO}, \mathrm{NO}_{2}, \mathrm{NO}_{3}, \mathrm{~N}_{2} \mathrm{O}, \mathrm{N}_{2} \mathrm{O}_{5}, \mathrm{HNO}_{3}, \mathrm{HNO}_{2}, \mathrm{HNO}, \mathrm{H}_{2} \mathrm{O}_{2}, \mathrm{~N}_{2}, \mathrm{O}_{2}, \mathrm{H}_{2}, \mathrm{CO}_{2}, \\
\mathrm{~N}_{2}(\mathrm{~A}), \mathrm{N}_{2}(\mathrm{~B}), \mathrm{N}_{2}(\mathrm{C}), \mathrm{N}_{2}\left(\mathrm{a}^{1}\right), \mathrm{N}_{2}\left(\mathrm{a}^{1}\right), \mathrm{O}_{2}(\mathrm{a}), \mathrm{O}_{2}(\mathrm{~b}), \mathrm{H}_{2} \mathrm{O}, \mathrm{HO}_{2}, \mathrm{OH}, \mathrm{OH}(\mathrm{v}), \mathrm{H}, \mathrm{HCl}, \mathrm{Cl}, \mathrm{ClO}\end{array}$ \\
\hline
\end{tabular}

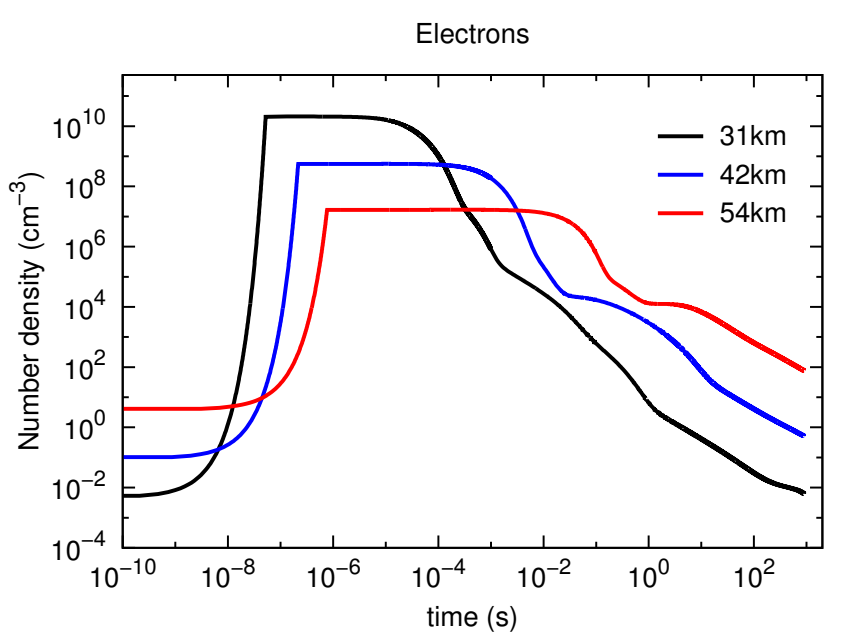

Fig. 1. Modelled evolution of the electron number density in a daytime sprite streamer at three selected altitudes.

Sentman et al. (2008a). Generally, there is very good agreement with the results of those model studies if the simulation parameters are the same. In particular this includes the electric field pulse, the rate coefficients of the electron impact reactions, and the concentration of the seed electrons. A study on the impact of those parameters on sprite chemistry simulations will be published elsewhere.

For the calculation of photo-dissociation and photoelectron detachment rates, the radiative transfer module of an atmospheric chemistry model (Winkler et al., 2009) is used. It originates from the model of Chipperfield (1999), and is based on the scheme of Lary and Pyle (1991). The calculation of photolysis rates of neutral compounds was already part of the model (C-177 to C-190 in the reaction scheme in the supplement to this paper). The model considers photoionisation of nitric oxide by solar Lyman- $\alpha$ radiation. Emissions from excited species are not accounted for.

Photo-destruction and photoelectron detachment of ions were added to the model. The rates for these processes are

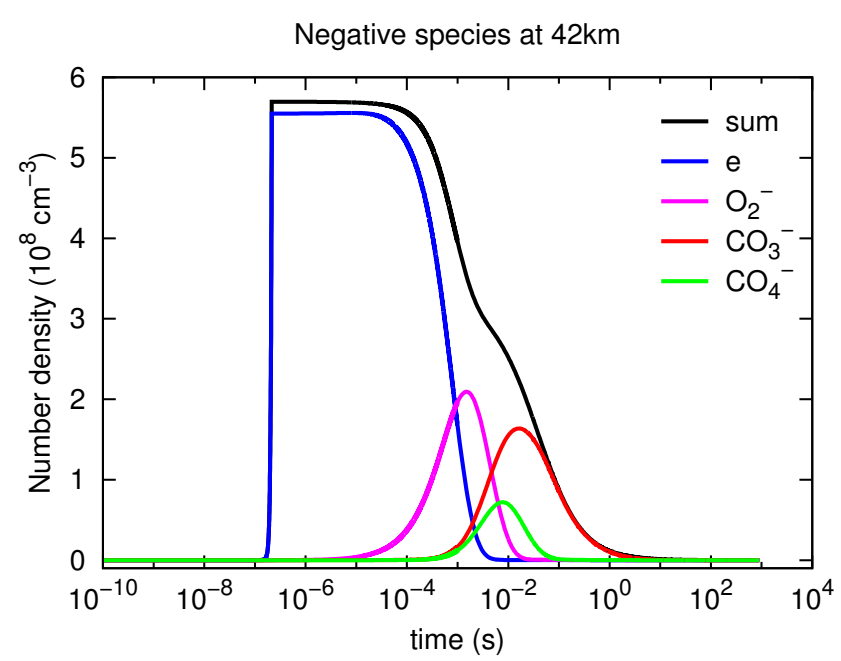

Fig. 2. Modelled evolution of the most abundant negative species in a daytime sprite streamer at $42 \mathrm{~km}$ altitude.

calculated using the actinic flux provided by the radiative transfer module and cross-section data from the literature. This is the same approach as in Winkler and Notholt (2013). The considered ion-photo reactions are listed in Table 3 . For the negative chlorine clusters $\mathrm{Cl}^{-}\left(\mathrm{H}_{2} \mathrm{O}\right), \mathrm{Cl}^{-}\left(\mathrm{CO}_{2}\right)$ and $\mathrm{Cl}^{-}(\mathrm{HCl})$ no photo-dissociation cross section could be found in the literature; the same applies to $\mathrm{O}^{-}\left(\mathrm{H}_{2} \mathrm{O}\right)$. Motivated by Ho et al. (1990), the photo-dissociation rates of these species are set equal to the rate of $\mathrm{NO}_{3}^{-}\left(\mathrm{H}_{2} \mathrm{O}\right)$ calculated with the cross-section data of Smith et al. (1979a); Hodges et al. (1980). Symmetric cations and $\mathrm{O}_{2}^{+}$clusters are known to have large photo-dissociation cross sections, but $\mathrm{NO}^{+}$ clusters and $\mathrm{H}_{3} \mathrm{O}^{+}$clusters have small cross sections (Smith et al., 1977; Smith and Lee, 1978). Therefore, only photodestruction of $\mathrm{N}_{4}^{+}, \mathrm{O}_{4}^{+}$, and $\mathrm{O}_{2}^{+}\left(\mathrm{H}_{2} \mathrm{O}\right)$ is considered in the model. 
Table 2. Electric field driven processes in the model. The reaction rate coefficients as functions of the reduced electric field are calculated with the Boltzmann solver BOLSIG+ (Hagelaar and Pitchford, 2005), and cross-section data from the literature. The reaction rate coefficient as a function of the reduced electric field, only for the last reaction, is directly taken from the reference.

\begin{tabular}{|c|c|c|c|}
\hline Reaction & & & Reference(s)* \\
\hline \multicolumn{4}{|l|}{ Ionisation } \\
\hline $\mathrm{e}+\mathrm{N}_{2}$ & $\rightarrow$ & $\mathrm{N}_{2}^{+}+2 \mathrm{e}$ & 1,2 \\
\hline $\mathrm{e}+\mathrm{N}_{2}$ & $\rightarrow$ & $\mathrm{N}^{7}+\mathrm{N}+2 \mathrm{e}$ & 2,3 \\
\hline $\mathrm{e}+\mathrm{N}_{2}$ & $\rightarrow$ & $\mathrm{N}^{+}+\mathrm{N}\left({ }^{2} \mathrm{D}\right)+2 \mathrm{e}$ & 3 \\
\hline $\mathrm{e}+\mathrm{O}_{2}$ & $\rightarrow$ & $\mathrm{O}_{2}^{+}+2 \mathrm{e}$ & 5 \\
\hline $\mathrm{e}+\mathrm{O}_{2}$ & $\rightarrow$ & $\mathrm{O}^{7}+\mathrm{O}+2 \mathrm{e}$ & 5 \\
\hline \multicolumn{4}{|c|}{ Attachment } \\
\hline $\mathrm{e}+\mathrm{O}_{2}$ & $\rightarrow$ & $\mathrm{O}^{-}+\mathrm{O}$ & 1 \\
\hline \multicolumn{4}{|c|}{ Dissociation } \\
\hline $\mathrm{e}+\mathrm{N}_{2}$ & $\rightarrow$ & $\mathrm{N}+\mathrm{N}+\mathrm{e}$ & 3,4 \\
\hline $\mathrm{e}+\mathrm{N}_{2}$ & $\rightarrow$ & $\mathrm{N}+\mathrm{N}\left({ }^{2} \mathrm{D}\right)+\mathrm{e}$ & 3 \\
\hline $\mathrm{e}+\mathrm{N}_{2}$ & $\rightarrow$ & $\mathrm{N}+\mathrm{N}\left({ }^{2} \mathrm{P}\right)+\mathrm{e}$ & 3 \\
\hline $\mathrm{e}+\mathrm{O}_{2}$ & $\rightarrow$ & $\mathrm{O}+\mathrm{O}+\mathrm{e}$ & 6 \\
\hline $\mathrm{e}+\mathrm{O}_{2}$ & $\rightarrow$ & $\mathrm{O}+\mathrm{O}\left({ }^{1} \mathrm{D}\right)+\mathrm{e}$ & 5 \\
\hline $\mathrm{e}+\mathrm{O}_{2}$ & $\rightarrow$ & $\mathrm{O}+\mathrm{O}\left({ }^{1} \mathrm{~S}\right)+\mathrm{e}$ & 7 \\
\hline \multicolumn{4}{|l|}{ Excitation } \\
\hline $\mathrm{e}+\mathrm{N}_{2}$ & $\rightarrow$ & $\mathrm{N}_{2}(\mathrm{~A})+\mathrm{e}$ & 1 \\
\hline $\mathrm{e}+\mathrm{N}_{2}$ & $\rightarrow$ & $\mathrm{N}_{2}(\mathrm{~B})+\mathrm{e}$ & 1 \\
\hline $\mathrm{e}+\mathrm{N}_{2}$ & $\rightarrow$ & $\mathrm{N}_{2}\left(\mathrm{a}^{\prime 1}\right)+\mathrm{e}$ & 1 \\
\hline $\mathrm{e}+\mathrm{N}_{2}$ & $\rightarrow$ & $\mathrm{N}_{2}\left(\mathrm{a}^{1}\right)+\mathrm{e}$ & 1 \\
\hline $\mathrm{e}+\mathrm{N}_{2}$ & $\rightarrow$ & $\mathrm{N}_{2}(\mathrm{C})+\mathrm{e}$ & 1 \\
\hline $\mathrm{e}+\mathrm{O}_{2}$ & $\rightarrow$ & $\mathrm{O}_{2}(\mathrm{a})+\mathrm{e}$ & 1 \\
\hline $\mathrm{e}+\mathrm{O}_{2}$ & $\rightarrow$ & $\mathrm{O}_{2}(\mathrm{~b})+\mathrm{e}$ & 1 \\
\hline \multicolumn{4}{|c|}{ Detachment } \\
\hline $\mathrm{O}^{-}+\mathrm{N}_{2}$ & $\rightarrow$ & $\mathrm{N}_{2} \mathrm{O}+\mathrm{e}$ & 8 \\
\hline
\end{tabular}

\section{Results}

Corresponding to the first daytime sprite event detected by Stanley et al. (2000), the model simulations were performed for latitude $27.5^{\circ} \mathrm{N}, 14$ August, 16:41 LT (local time), almost two hours before sunset (solar zenith angle $\sim 65^{\circ}$ ). Figure 1 shows the modelled evolution of the electron density under the influence of the electric field pulse at the tip of a streamer at $31 \mathrm{~km}, 42 \mathrm{~km}$, and $54 \mathrm{~km}$. At all altitudes there is a rapid increase of the electron density by orders of magnitude during the pulse. The peak electron density is largest at $31 \mathrm{~km}$, and smallest at $54 \mathrm{~km}$. This is because the number of electrons produced in the streamer tip scales with the
Table 3. Photoelectron detachment, photo-dissociation of ions, and photo-ionisation in the model. The rate coefficients are calculated using cross-section data from the references.

\begin{tabular}{|c|c|c|c|}
\hline Reaction & & & Reference(s)* \\
\hline \multicolumn{4}{|c|}{ Electron detachment } \\
\hline $\mathrm{O}^{-}+h v$ & $\rightarrow$ & $\mathrm{e}+\mathrm{O}$ & 1,2 \\
\hline $\mathrm{O}_{2}^{-}+h v$ & $\rightarrow$ & $\mathrm{e}+\mathrm{O}_{2}$ & 1,2 \\
\hline $\mathrm{O}_{3}^{-}+h v$ & $\rightarrow$ & $\mathrm{e}+\mathrm{O}_{3}$ & 3 \\
\hline $\mathrm{O}_{4}^{-}+h v$ & $\rightarrow$ & $\mathrm{e}+\mathrm{O}_{2}+\mathrm{O}_{2}$ & 1 \\
\hline $\mathrm{CO}_{4}^{-}+h v$ & $\rightarrow$ & $\mathrm{e}+\mathrm{CO}_{2}+\mathrm{O}_{2}$ & 2,3 \\
\hline $\mathrm{OH}^{-}+h v$ & $\rightarrow$ & $\mathrm{e}+\mathrm{OH}$ & 1 \\
\hline $\mathrm{NO}^{-}+h v$ & $\rightarrow$ & $\mathrm{e}+\mathrm{NO}$ & 4 \\
\hline $\mathrm{NO}_{2}^{-}+h v$ & $\rightarrow$ & $\mathrm{e}+\mathrm{NO}_{2}$ & 2,5 \\
\hline $\mathrm{NO}_{3}^{-}+h v$ & $\rightarrow$ & $\mathrm{e}+\mathrm{NO}_{3}$ & $2,5,6$ \\
\hline $\mathrm{O}_{2}^{-}\left(\mathrm{H}_{2} \mathrm{O}\right)+h v$ & $\rightarrow$ & $\mathrm{e}+\mathrm{H}_{2} \mathrm{O}+\mathrm{O}_{2}$ & 1 \\
\hline $\mathrm{Cl}^{-}+h v$ & $\rightarrow$ & $\mathrm{e}+\mathrm{Cl}$ & 7,8 \\
\hline $\mathrm{ClO}^{-}+h v$ & $\rightarrow$ & $\mathrm{e}+\mathrm{ClO}$ & 9 \\
\hline
\end{tabular}

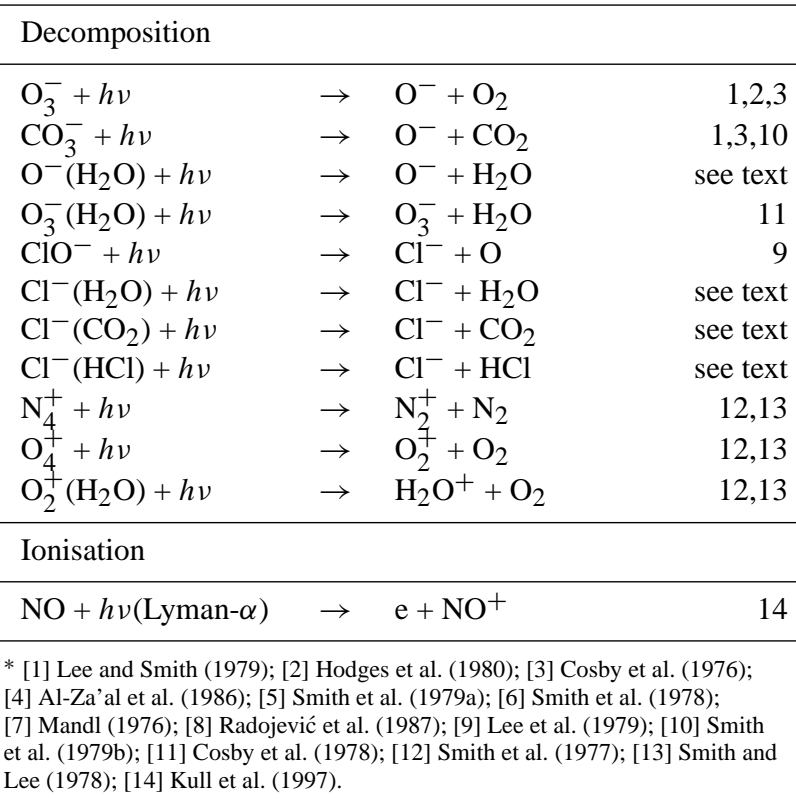

square of the air density (Eq. 2 in Sect. 3.1). The relaxation to background values is faster at lower altitudes due to pressure dependent electron loss reactions such as attachment to $\mathrm{O}_{2}$ and three-body recombination with positive ions. If not stated otherwise, the results presented in the following are for an altitude of $42 \mathrm{~km}$. Figure 2 depicts the concentrations of electrons and the most abundant negative ions as a function of time. The electrons liberated during the electric field pulse undergo attachment to $\mathrm{O}_{2}$, and after $\sim 1 \mathrm{~ms}, \mathrm{O}_{2}^{-}$has become the principal anion. Eventually $\mathrm{CO}_{3}^{-}$and $\mathrm{CO}_{4}^{-}$are formed. A few seconds after the electric field pulse, the total charge density is back to pre-breakdown values. In comparison to higher altitudes (Gordillo-Vázquez, 2008), the peak ion concentration is higher but the "ionic phase" is shorter. The main positive ions are shown in Fig. 3. Just after the 


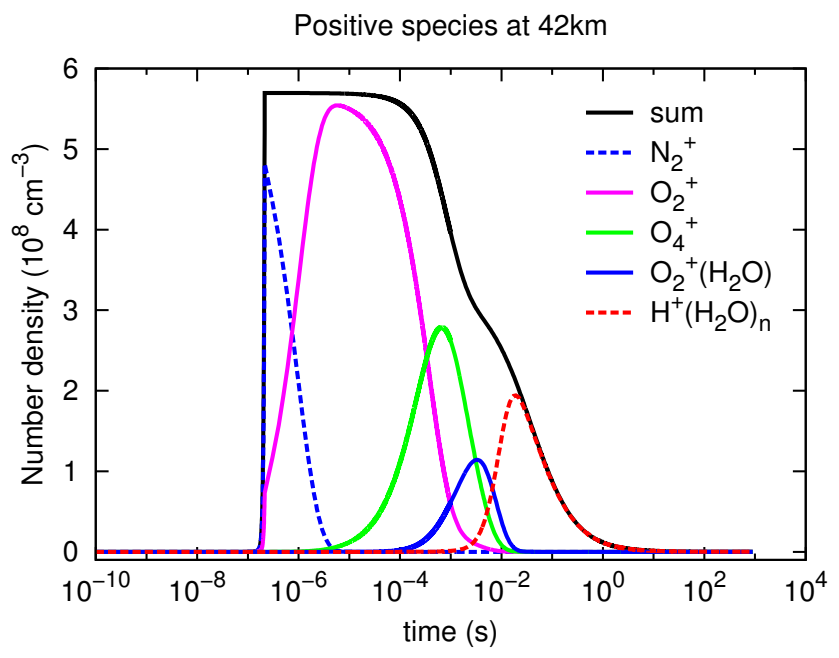

Fig. 3. Modelled evolution of the most abundant positive ions in a daytime sprite streamer at $42 \mathrm{~km}$ altitude.

electric field pulse, $\mathrm{N}_{2}^{+}$is the most abundant cation. Rapid charge exchange with $\mathrm{O}_{2}$ leads to a production of $\mathrm{O}_{2}^{+}$from which heavier cluster ions are formed. The abundance of $\mathrm{N}_{2} \mathrm{O}_{2}^{+}$(not shown) is always small. This is in contrast to the sprite model predictions of Sentman et al. (2008a) and Gordillo-Vázquez (2008). The reason for this are the additionally included loss reactions with $\mathrm{N}_{2}$ and $\mathrm{O}_{2}$ (Kossyi et al., 1992), as well as with $\mathrm{H}_{2} \mathrm{O}$ (Howard et al., 1972) (P-53 to P55 in the reaction scheme in the supplement to this paper). On the short timescale of the ionic phase, photo-processes turn out to be negligible. The results (not shown) of a test simulation with deactivated photoelectron detachment and photodissociation basically do not differ from the results just presented.

In the remaining section, the impact of the sprite streamer on neutral species will be discussed. The focus lies on nitrogen, hydrogen and oxygen, and in particular on ozone perturbations. In order to compare the chemical effects in a daytime sprite streamer with those in a night-time sprite streamer, an additional simulation was carried out for midnight (same location, same day). In Fig. 4 the response of oxygen species to the electric field pulse is shown for both daytime and for night-time conditions. The concentration of atomic oxygen increases due to electron impact dissociation of $\mathrm{O}_{2}$, but it is always significantly smaller than the concentration of $\mathrm{O}_{3}$. The lifetime of the ground-state atomic oxygen produced during the electric breakdown is of the order of a few seconds. For daytime conditions, there is a small concentration of atomic oxygen before and after the sprite event, mainly due to photolysis of $\mathrm{O}_{2}$ and $\mathrm{O}_{3}$. This is important for the interaction of oxygen and nitrogen species as discussed below. The evolution of the most important hydrogen species is shown in Fig. 5. As a result of the electric breakdown, there is significant production of hydroxyl molecules, followed by
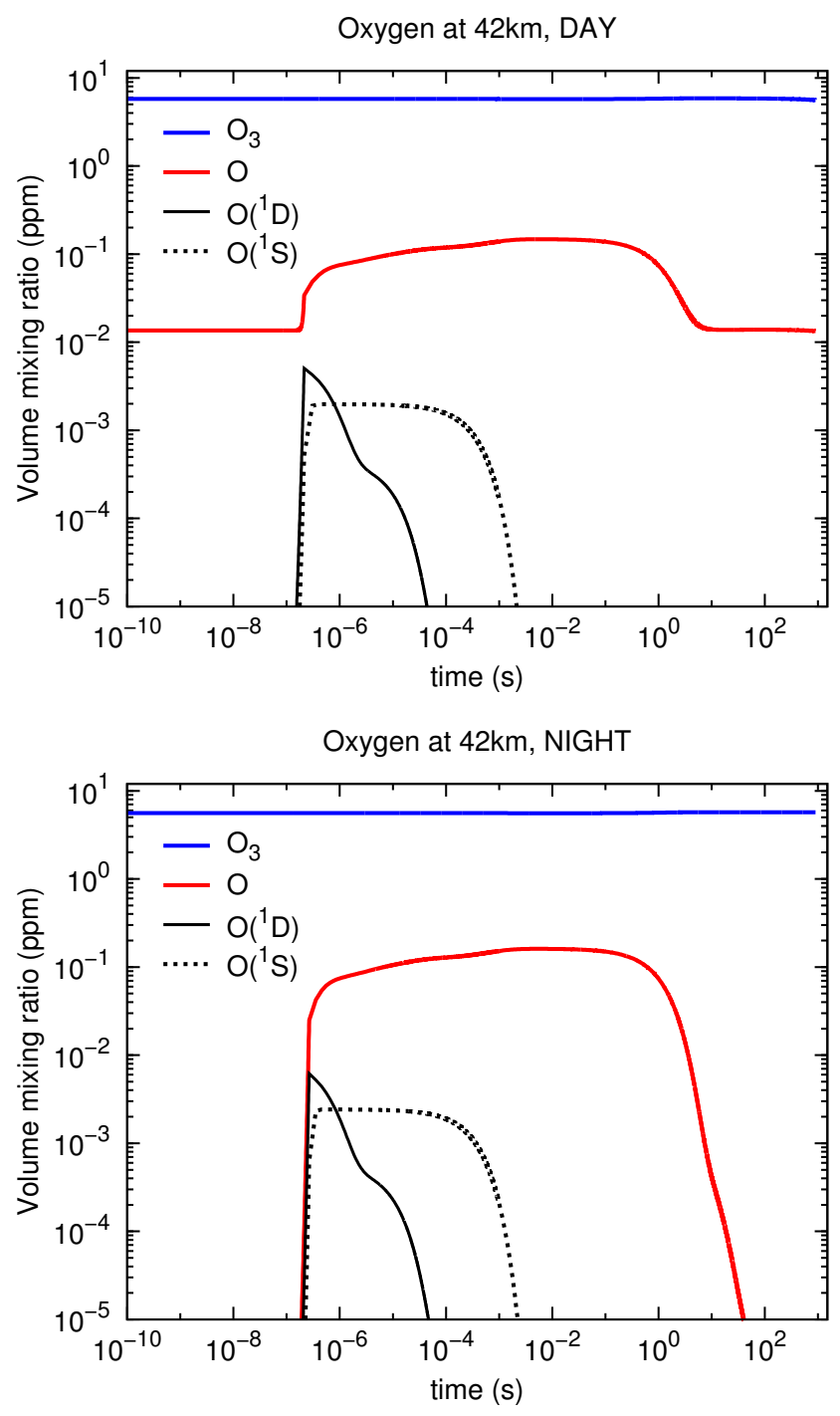

Fig. 4. Modelled evolution of the volume mixing ratios of oxygen species in a sprite streamer at $42 \mathrm{~km}$ altitude. Upper panel: daytime; lower panel: night-time.

an increase of $\mathrm{HO}_{2}$. After a few minutes, the concentration of $\mathrm{OH}$ is basically back to pre-breakdown values, $\mathrm{HO}_{2}$ has started to decreased again, and $\mathrm{H}_{2} \mathrm{O}_{2}$ has increased. All this is similar for both daytime and night-time events. On the contrary, concerning nitrogen species, there are considerable differences between daytime and night-time as shown in Fig. 6 . Electron impact dissociation of $\mathrm{N}_{2}$ leads to a significant increase of nitrogen atoms followed by a rapid production of nitric oxide. An important subsequent reaction of nitric oxide is the destruction of ozone molecules:

$\mathrm{NO}+\mathrm{O}_{3} \rightarrow \mathrm{NO}_{2}+\mathrm{O}_{2}$.

In the night-time atmosphere, $\mathrm{NO}_{2}$ is rather stable. It becomes the principal $\mathrm{NO}_{\mathrm{x}}$ species a few seconds after the electric breakdown. The concentration of NO decreases 

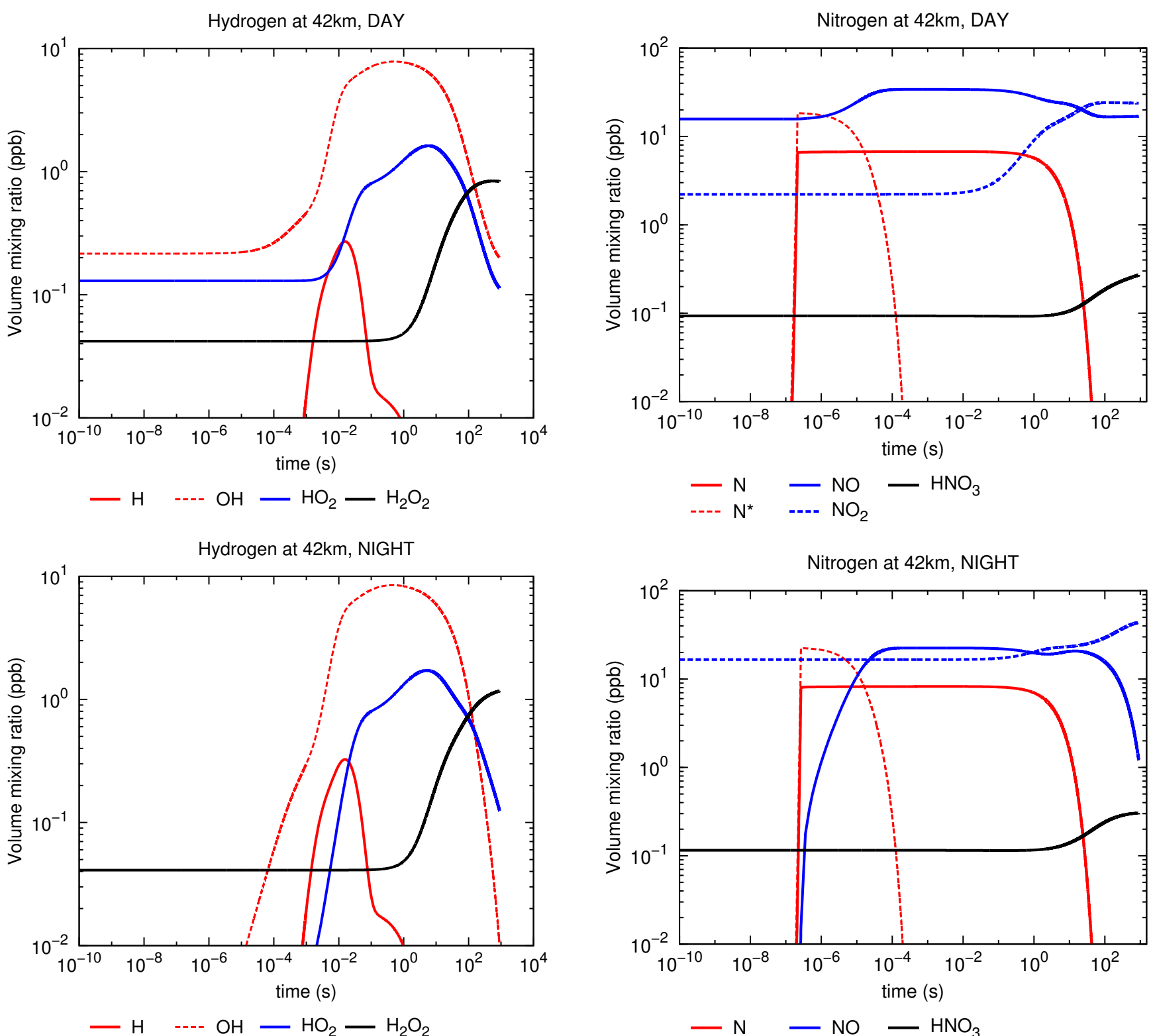

Fig. 5. Modelled evolution of the volume mixing ratios of hydrogen species in a sprite streamer at $42 \mathrm{~km}$ altitude. Upper panel: daytime; lower panel: night-time.

continuously (Fig. 6). In contrast to that, in the daytime atmosphere there are reactions converting $\mathrm{NO}_{2}$ back into nitric oxide, in particular:

$\mathrm{NO}_{2}+\mathrm{O} \rightarrow \mathrm{NO}+\mathrm{O}_{2}$,

and

$\mathrm{NO}_{2}+h v \rightarrow \mathrm{NO}+\mathrm{O}$

As a result, $\mathrm{NO}$ is recycled back from $\mathrm{NO}_{2}$, and the Reactions (R6) and (R7)/(R8) constitute a catalytic ozone destruction cycle. Figure 7 shows the most important loss reactions of ozone for the daytime sprite streamer. It can be

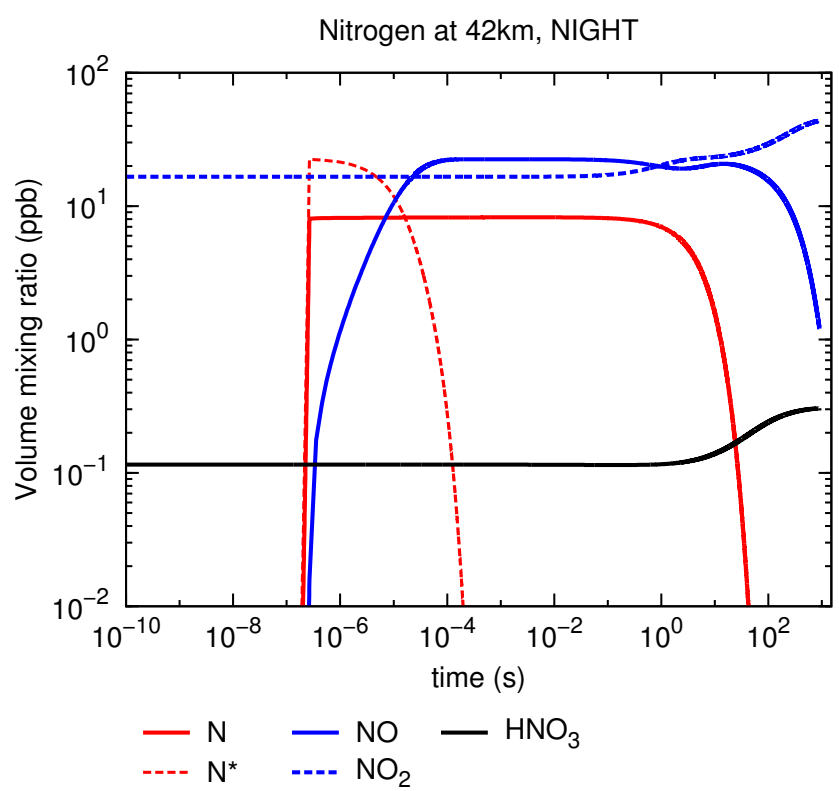

Fig. 6. Modelled evolution of the volume mixing ratios of nitrogen species in a sprite streamer at $42 \mathrm{~km}$ altitude. Upper panel: daytime; lower panel: night-time.

seen that, after a few seconds $\mathrm{OH}+\mathrm{O}_{3}$ is the main ozone sink, and after some minutes it is Reaction (R6). While the former also takes place in the night-time case, the latter is basically missing in the night-time atmosphere as almost all $\mathrm{NO}_{\mathrm{x}}$ is in form of $\mathrm{NO}_{2}$ after some minutes (Fig. 6). Therefore, the impact of a daytime sprite streamer on ozone differs from the effect of a night-time sprite streamer. This is clearly demonstrated in Fig. 8 where the relative change of ozone in the sprite streamer at three selected altitudes is shown. While there is basically no effect on $\mathrm{O}_{3}$ at $54 \mathrm{~km}$ for the night-time event, the catalytic ozone destruction during daytime causes 
Ozone loss processes at $42 \mathrm{~km}$

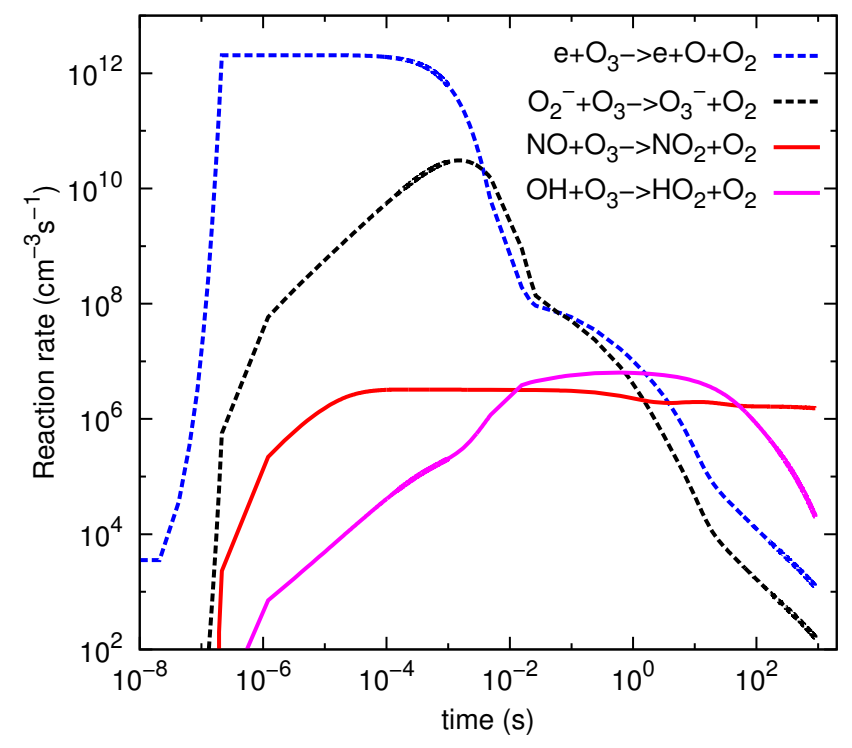

Fig. 7. The four most important ozone loss reactions in a daytime sprite streamer at $42 \mathrm{~km}$. Shown are the two main (dotted) ionic and (solid) neutral processes.

a continuous decrease of ozone exceeding $15 \%$ after $15 \mathrm{~min}$ of model time.

At lower altitudes, there is initially a decrease of ozone due to ionic ozone loss reactions, in particular those shown in Fig. 7. This is followed by an increase of ozone resulting from the liberation of oxygen atoms during the electric pulse. In terms of relative change, this effect increases with air number density $N$ because the amount of oxygen atoms produced scales with the number of electrons behind the streamer tip $\left(\sim N^{2}\right)$, whereas the atmospheric $\mathrm{O}_{3}$ roughly scales with $N$. During the night, the enhanced ozone values are basically stable, but in the sunlit atmosphere, ozone eventually decreases (Fig. 8). The fact that the $\mathrm{NO}_{\mathrm{x}}$ catalyzed ozone decrease is less pronounced at lower altitudes can be understood by the following considerations: at lower altitudes, the three body reaction $\mathrm{O}+\mathrm{O}_{2}+\mathrm{M} \rightarrow \mathrm{O}_{3}+\mathrm{M}$ is faster than at higher altitudes. This reaction produces ozone and competes with Reaction (R7). Furthermore, the $\mathrm{NO}_{2}$ photolysis frequency of Reaction (R8) is smaller than at higher altitudes. Therefore, the rate at which $\mathrm{NO}$ is recycled from $\mathrm{NO}_{2}$ is smaller at lower altitudes.

In order to put the results into context, Fig. 9 shows the modelled diurnal cycle of ozone, and the streamer ozone values. In this Figure, the changes during the fifteen minutes of the streamer model time can hardly be resolved. However, it gives an impression of how the sprite streamer ozone changes compare to the diurnal variations. At $54 \mathrm{~km}$, ozone has decreased by about $250 \mathrm{ppb}$ in the daytime sprite streamer after fifteen minutes. This values is of the same order as the diurnal ozone variation at that altitude. Again it is apparent
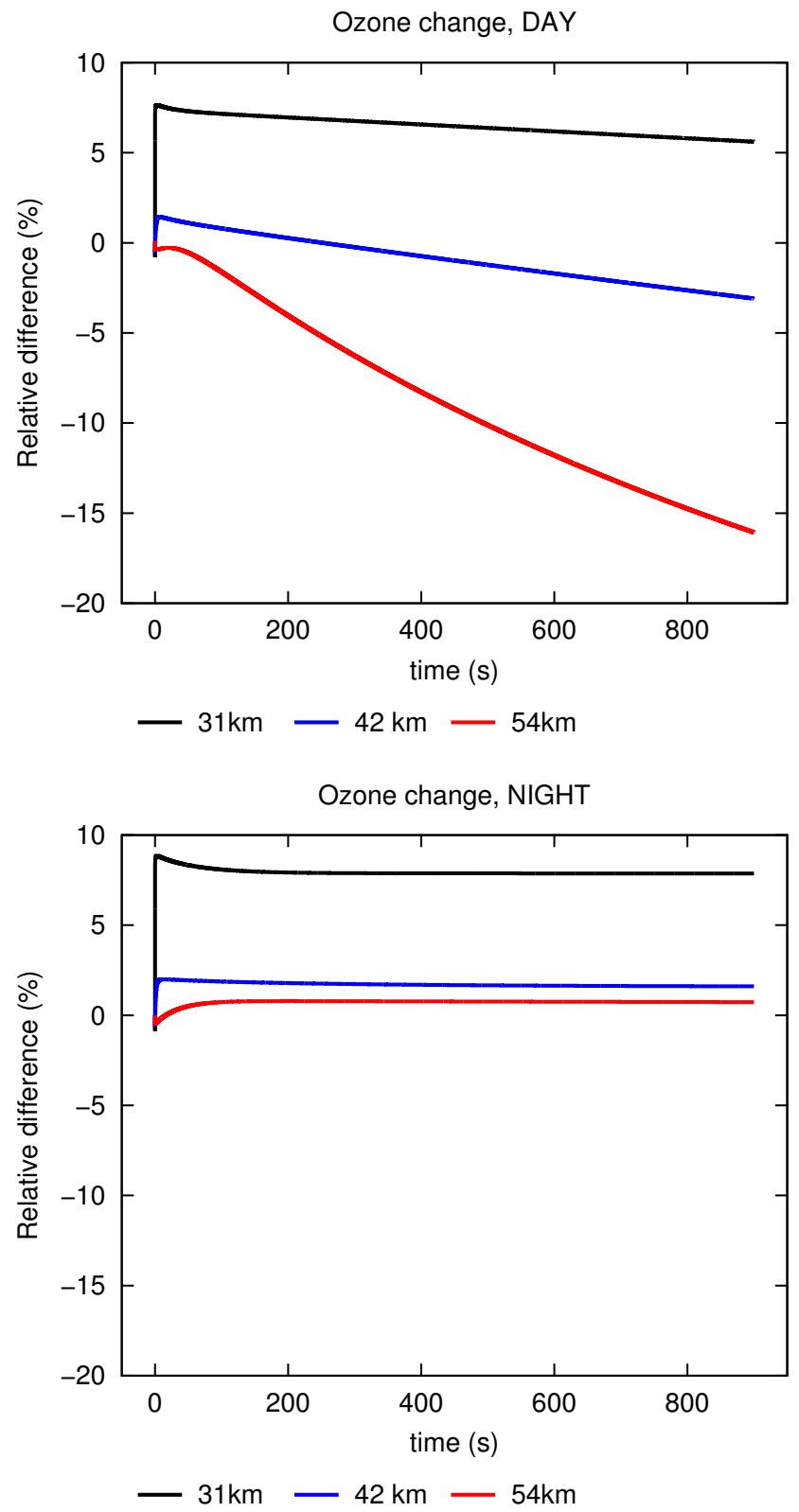

Fig. 8. Modelled change of ozone in sprite streamers at three selected altitudes. Upper panel: daytime; lower panel: night-time.

that the night-time event has basically no effect at $54 \mathrm{~km}$. At $42 \mathrm{~km}$, ozone increases by about $100 \mathrm{ppb}$ in both night-time and daytime streamer. In the daytime case this is followed by a rapid ozone decrease of more than $100 \mathrm{ppb}$ compared to the initial ozone value. At $31 \mathrm{~km}$, the impact of daytime and night-time streamer are very similar; both of them lead to an ozone increase of almost $800 \mathrm{ppb}$. 

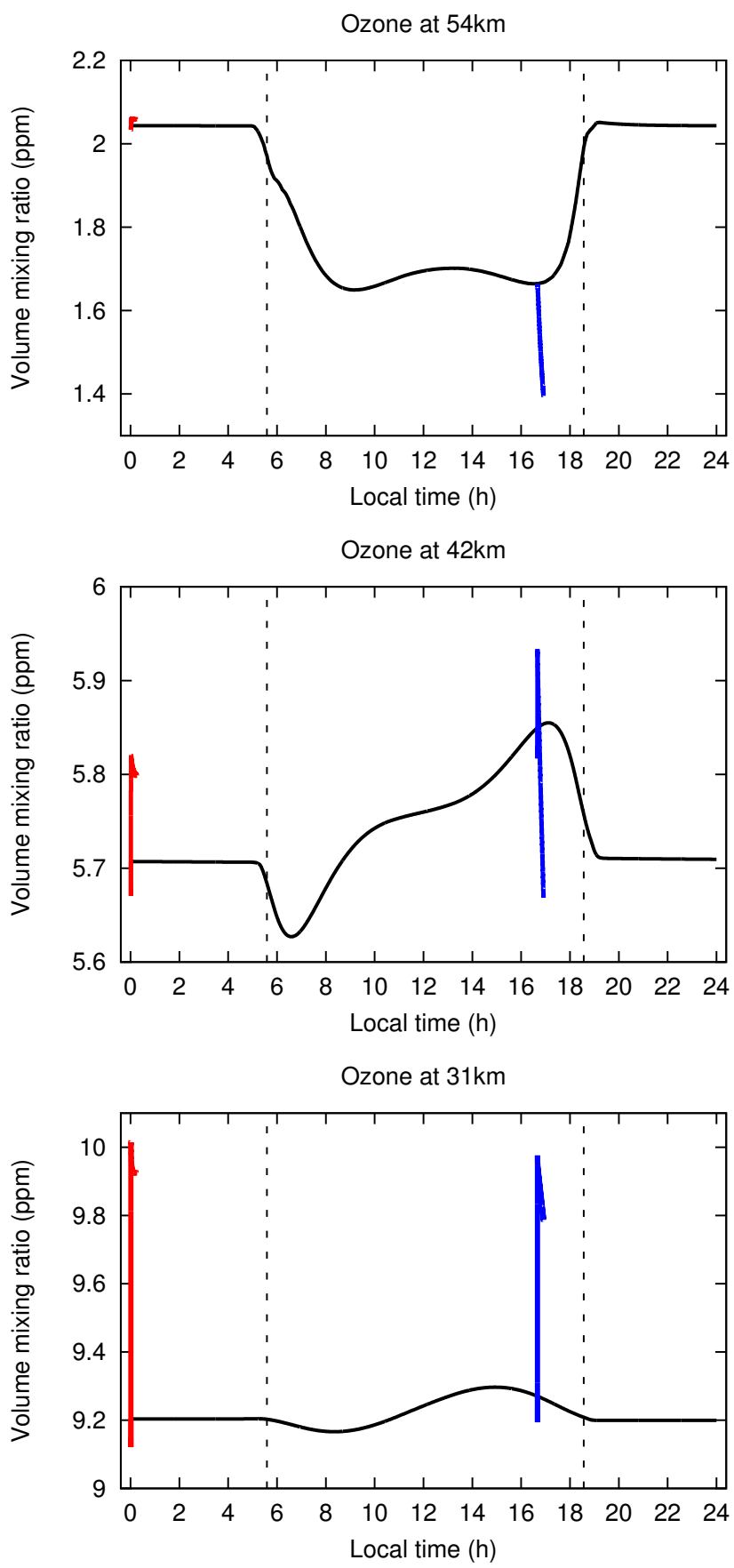

Fig. 9. Modelled ozone as a function of local time for latitude $27.5^{\circ} \mathrm{N}, 14$ August at three selected altitudes. The solid black line shows the undisturbed diurnal cycle. Superimposed are the streamer ozone values for the night-time event (midnight, red), and the daytime event (16:41 LT, blue). The dashed black lines depict sunrise and sunset, respectively.

\section{Summary and conclusions}

The chemical processes in daytime sprite streamers in the upper stratosphere have been investigated by means of a detailed ion-neutral chemistry model. As transport processes such as diffusive mixing with ambient air are neglected, the simulations are limited to $15 \mathrm{~min}$ after the passage of the streamer tip. For comparison, additional model simulations for night-time conditions have been carried out. The model results indicate that the ozone perturbations due to daytime sprites streamers differ considerably from the ones of nighttime events, in particular at higher altitudes.

Initial effects of the breakdown electric fields at the tip of sprite streamers include a short-term loss of ozone due to ion-chemical reactions, and a production of atomic oxygen. The latter leads to a formation of ozone. In terms of relative ozone change, this effect decreases with altitude. Additionally, reactive nitrogen is produced at the streamer heads. For night-time conditions, this reactive nitrogen is rapidly converted into significantly less reactive $\mathrm{NO}_{2}$, and there is basically no ozone depletion. The situation is different for daytime conditions where $\mathrm{NO}_{\mathrm{x}}$ causes catalytic ozone destruction. As a consequence, there is significant ozone loss in sprite streamers in the daytime atmosphere, in particular at higher altitudes. At an altitude of $54 \mathrm{~km}$, ozone has decreased by about $15 \%$ fifteen minutes after the sprite event.

Note that the presented model results give only a first indication of the chemical effects of daytime sprite streamers in comparison with their night-time counterparts. For the assessment of chemical effects on longer timescales, mixing of the streamer gas with the ambient air will have to be taken into account.

\section{Supplementary material related to this article is available online at http://www.atmos-chem-phys.net/14/ 3545/2014/acp-14-3545-2014-supplement.pdf.}

Acknowledgements. The authors would like to thank the anonymous reviewers for their helpful comments and suggestions to improve the quality of the paper. H. Winkler is indebted to Francisco J. Gordillo-Vázquez at IAA-CSIC, Granada, for helpful discussions on plasma chemistry, and for model comparisons. Financial support by the University of Bremen is gratefully acknowledged.

Edited by: P. Jöckel 


\section{References}

Adachi, T., Hiraki, Y., Yamamoto, K., Takahashi, Y., Fukunishi, H., Hsu, R.-R., Su, H.-T., Chen, A. B., Mende, S. B., Frey, H. U., and Lee, L. C.: Electric fields and electron energies in sprites and temporal evolutions of lightning charge moment, J. Appl. Phys. D, 41, 234010, doi:10.1088/0022-3727/41/23/234010, 2008.

Al-Za'al, M., Miller, H. C., and Farley, J. W.: Measurement of the infrared photodetachment cross section of $\mathrm{NO}^{-}$, Phys. Rev. A, 33, 977-985, doi:10.1103/PhysRevA.33.977, 1986.

Arnone, E., Kero, A., Enell, C.-F., Carlotti, M., Rodger, C. J., Papandrea, E., Arnold, N. F., Dinelli, B. M., Ridolfi, M., and Turunen, E.: Seeking sprite-induced signatures in remotely sensed middle atmosphere $\mathrm{NO}_{2}$ : latitude and time variations, Plasma Sources Sci. T., 18, 034014, doi:10.1088/09630252/18/3/034014, 2009.

Boccippio, D. J., Williams, E. R., Heckman, S. J., Lyons, W. A., Baker, I. T., and Boldi, R.: Sprites, ELF Transients, and Positive Ground Strokes, Science, 269, 1088-1091, 1995.

Boeck, W. L., Jr., O. H. V., Blakeslee, R. J., Vonnegut, B., Brook, M., and McKune, J.: Observations of lightning in the stratosphere, J. Geophys. Res., 100, 1465-1475, doi:10.1029/94JD02432, 1995.

Bór, J.: Optically perceptible characteristics of sprites observed in Central Europe in 2007-2009, J. Atmos. Sol.-Terr. Phys., 92, 151-177, doi:10.1016/j.jastp.2012.10.008, 2013.

Borisov, N. D., Kozlov, I., S., and Smirnova, N. V.: Changes in the chemical composition of the middle atmosphere during multiple microwave pulse discharge in the air, Cosmic Res.+, 31, 117186, 1993.

Bowers, M. T., Illies, A. J., and Jarrold, M. F.: On the structure and photodissociation of cluster ions in the gas phase. (N2) $(\mathrm{O} 2+)$ and (NO)2+, Chem. Phys. Lett., 102, 335-339, doi:10.1016/00092614(83)87052-3, 1983.

Chen, A. B., Kuo, C.-L., Lee, Y.-J., Su, H.-T., Hsu, R.-R., Chern, J.-L., Frey, H., Mende, S., Takahashi, Y., Fukunishi, H., Chang, Y.-S., Liu, T.-Y., and Lee, L.-C.: Global distributions and occurrence rates of transient luminous events, J. Geophys. Res., 113, doi:10.1029/2008JA013101, http://www.agu. org/pubs/crossref/2008/2008JA013101.shtml, 2008.

Chipperfield, M. P.: Multiannual simulations with a threedimensional chemical transport model, J. Geophys. Res., 104, 1781-1805, doi:10.1029/98JD02597, 1999.

Cho, M. and Rycroft, M. J.: Computer simulation of the electric field structure and optical emission from cloud-top to the ionosphere, J. Atmos. Sol.-Terr. Phys., 60, 871-888, doi:10.1016/S1364-6826(98)00017-0, 1998.

Cosby, P. C.: Electron-impact dissociation of nitrogen, J. Chem. Phys., 98, 9544-9553, doi:10.1063/1.464385, 1993a.

Cosby, P. C.: Electron-impact dissociation of oxygen, J. Chem. Phys., 98, 9560-9569, doi:10.1063/1.464387, 1993b.

Cosby, P. C., Ling, J. H., Peterson, J. R., and Moseley, J. T.: Photodissociation and photodetachment of molecular negative ions. III. Ions formed in $\mathrm{CO}_{2} / \mathrm{O}_{2} / \mathrm{H}_{2}$ mixtures, J. Chem. Phys., 65, 5267-5274, doi:10.1063/1.433026, 1976.

Cosby, P. C., Smith, G. P., and Moseley, J. T.: Photodissociation and photodetachment of molecular negative ions. IV. Hydrates of $\mathrm{O}_{3}^{-}$, J. Chem. Phys., 69, 2779-2781, doi:10.1063/1.436875, 1978 .
Cummer, S. A., Jaugey, N., Li, J., Lyons, W. A., Nelson, T. E., and Gerken, E. A.: Submillisecond imaging of sprite development and structure, Geophys. Res. Lett., 33, L04104, doi:10.1029/2005GL024969, 2006.

Deyerl, H.-J., Clements, T. G., Luong, A. K., and Continetti, R. E.: Transition state dynamics of the $\mathrm{OH}+\mathrm{OH} \rightarrow \mathrm{O}+\mathrm{H}_{2} \mathrm{O}$ reaction studied by dissociative photodetachment of $\mathrm{H}_{2} \mathrm{O}_{2}^{-}$, J. Chem. Phys., 115, 6931-6940, doi:10.1063/1.1404148, 2001.

Enell, C.-F., Arnone, E., Adachi, T., Chanrion, O., Verronen, P. T., Seppälä, A., Neubert, T., Ulich, T., Turunen, E., Takahashi, Y., and Hsu, R.-R.: Parameterisation of the chemical effect of sprites in the middle atmosphere, Ann. Geophys., 26, 13-27, doi:10.5194/angeo-26-13-2008, 2008.

Evtushenko, A. and Mareev, E.: Simulation of mesosphericcomposition disturbances under the action of high-altitude discharges (sprites), Radiophys. Quantum El., 54, 111-127, doi:10.1007/s11141-011-9275-7, 2011.

Farges, T., Blanc, E., Pichon, A. L., Neubert, T., and Allin, T. H.: Identification of infrasound produced by sprites during the Sprite2003 campaign, Geophys. Res. Lett., 32, L01813, doi:10.1029/2004GL021212, 2005.

Fernsler, R. F. and Rowland, H. L.: Models of lightningproduced sprites and elves, J. Geophys. Res., 101, 29653-29662, doi:10.1029/96JD02159, 1996.

Franz, R. C., Nemzek, R. J., and Winckler, J. R.: Television Image of a Large Upward Electrical Discharge Above a Thunderstorm System, Science, 249, 48-51, doi:10.1126/science.249.4964.48, 1990.

Gamerota, W. R., Cummer, S. A., Li, J., Stenbaek-Nielsen, H. C., Haaland, R. K., and McHarg, M. G.: Comparison of sprite initiation altitudes between observations and models, J. Geophys. Res., 116, A02317, doi:10.1029/2010JA016095, 2011.

Gordillo-Vázquez, F. J.: Air plasma kinetics under the influence of sprites, J. Appl. Phys. D, 41, 234016, doi:10.1088/00223727/41/23/234016, 2008.

Hagelaar, G. J. M. and Pitchford, L. C.: Solving the Boltzmann equation to obtain electron transport coefficients and rate coefficients for fluid models, Plasma Sources Sci. Technol., 14, 722733, doi:10.1088/0963-0252/14/4/011, 2005.

Hiraki, Y., Tong, L., Fukunishi, H., Nanbu, K., Kasai, Y., and Ichimura, A.: Generation of metastable oxygen atom $\mathrm{O}\left({ }^{1} \mathrm{D}\right)$ in sprite halos, Geophys. Res. Lett., 31, L14105, doi:10.1029/2004GL020048, 2004.

Hiraki, Y., Kasai, Y., and Fukunishi, H.: Chemistry of sprite discharges through ion-neutral reactions, Atmos. Chem. Phys., 8, 3919-3928, doi:10.5194/acp-8-3919-2008, 2008.

Ho, D., Tsang, K., Wong, A., and Siverson, R.: Stratospheric Ozone Conservation by Electron Attachment to Chlorine Atoms - The Negative-Ion Chemistry in Controlled Active Global Experiments (CAGE) Proceedings (E. Sindoni and A. Y. Wong), Bologna, Lawrence Livermore National Lab., CA (USA), 1990.

Hodges, R. V., Lee, L. C., and Moseley, J. T.: Photodissociation and photodetachment of molecular negative ions. IX. Atmospheric ions at 2484 and $3511 \AA$ A, J. Chem. Phys., 72, 2998-3000, doi:10.1063/1.439500, 1980.

Howard, C., Bierbaum, V., Rundle, H., and Kaufman, F.: Kinetics and Mechanism of the Formation of Water Cluster Ions from $\mathrm{O}_{2}^{+}$and $\mathrm{H}_{2} \mathrm{O}$, J. Chem. Phys., 57, 3491-3497, doi:10.1063/1.1678783, 1972. 
Hu, W., Cummer, S. A., and Lyons, W. A.: Testing sprite initiation theory using lightning measurements and modeled electromagnetic fields, J. Geophys. Res., 112, D13115, doi:10.1029/2006JD007939, 2007.

Itikawa, Y.: Cross Sections for Electron Collisions with Nitrogen Molecules, J. Phys. Chem. Ref. Dat., 35, 31-53, doi:10.1063/1.1937426, 2006.

Itikawa, Y.: Cross Sections for Electron Collisions with Oxygen Molecules, J. Phys. Chem. Ref. Dat., 38, 1-20, doi:10.1063/1.3025886, 2009.

Kazil, J.: The University of Bern atmospheric ion model: Timedependent ion modeling in the stratosphere, mesosphere and lower thermosphere, Ph.D. thesis, University of Bern, Switzerland, 2002.

Kossyi, I., Kostinsky, A., Matveyev, A., and V.P.Silakov: Kinetic scheme of the non-equlibrium discharge in nitrogen-oxygen mixtures, Plasma Sources Sci. T., 1, 207-220, 1992.

Kull, A., Kopp, E., Granier, C., and Brasseur, G.: Ions and electrons of the lower-latitude D region, J. Geophys. Res., 102, 97059716, 1997.

Kumar, S., Kumar, A., and Rodger, C.: Subionospheric early VLF perturbations observed at Suva: VLF detection of red sprites in the day?, J. Geophys. Res., 113, A03311, doi:10.1029/2007JA012734, 2008.

Lary, D. J. and Pyle, J. A.: Diffuse radiation, twilight, and photochemistry - I, J. Atmos. Chem., 13, 373-392, doi:10.1007/BF00057753, 1991.

LeClair, L. R. and McConkey, J. W.: Selective detection of $\mathrm{O}\left({ }^{1} \mathrm{~S}\right)$ following electron impact dissociation of $\mathrm{O}_{2}$ and $\mathrm{N}_{2} \mathrm{O}$ using a XeO* conversion technique, J. Chem. Phys., 99, 4566-4577, doi:10.1063/1.466056, 1993.

Lee, L. C. and Smith, G. P.: Photodissociation and photodetachment of molecular negative ions. VI. Ions in $\mathrm{O}_{2} / \mathrm{CH}_{4} / \mathrm{H}_{2} \mathrm{O}$ mixtures from 3500 to $8600 \AA$, J. Chem. Phys., 70, 1727-1735, doi:10.1063/1.437690, 1979 .

Lee, L. C., Smith, G. P., Moseley, J. T., Cosby, P. C., and Guest, J. A.: Photodissociation and photodetachment of $\mathrm{Cl}_{2}^{-}$, $\mathrm{ClO}^{-}, \mathrm{Cl}_{3}^{-}$and $\mathrm{BrCl}_{2}^{-}$, J. Chem. Phys., 70, 3237-3246, doi:10.1063/1.437897, 1979.

Lehtinen, N. G. and Inan, U. S.: Possible persistent ionization caused by giant blue jets, Geophys. Res. Lett., 34, L08804, doi:10.1029/2006GL029051, 2007.

Luque, A. and Gordillo-Vázquez, F. J.: Mesospheric electric breakdown and delayed sprite ignition caused by electron detachment, Nat. Geosci., 5, 22-25, 2012.

Mandl, A.: Electron photodetachment cross sections of $\mathrm{Cl}^{-}$and $\mathrm{Br}^{-}$, Phys. Rev. A, 14, 345-348, doi:10.1103/PhysRevA.14.345, 1976

McHarg, M. G., Stenbaek-Nielsen, H. C., and Kammae, T.: Observations of streamer formation in sprites, Geophys. Res. Lett., 34, L06804, doi:10.1029/2006GL027854, 2007.

Moudry, D., Stenbaek-Nielsen, H., Sentman, D., and Wescott, E.: Imaging of elves, halos and sprite initiation at $1 \mathrm{~ms}$ source time resolution, J. Atmos. Solar-Terr. Phys., 65, 509-518, doi:10.1016/S1364-6826(02)00323-1, 2003.

Neubert, T., Rycroft, M., Farges, T., Blanc, E., Chanrion, O., Arnone, E., Odzimek, A., Arnold, N., Enell, C.-F., Turunen, E., Bösinger, T., Mika, Ã., Haldoupis, C., Steiner, R. J., Velde, O., Soula, S., Berg, P., Boberg, F., Thejll, P., Christiansen, B., Ignac- colo, M., Füllekrug, M., Verronen, P., Montanya, J., and Crosby, N.: Recent Results from Studies of Electric Discharges in the Mesosphere, Surv. Geophys., 29, 71-137, doi:10.1007/s10712008-9043-1, 2008.

Pasko, V. P. and Stenbaek-Nielsen, H. C.: Diffuse and streamer regions of sprites, Geophys. Res. Lett., 29, 1440, doi:10.1029/2001GL014241, 2002.

Pasko, V. P., Inan, U. S., Taranenko, Y. N., and Bell, T. F.: Heating, ionization and upward discharges in the mesosphere, due to intense quasi-electrostatic thundercloud fields, Geophys. Res. Lett., 22, 365-368, doi:10.1029/95GL00008, 1995.

Pasko, V. P., Inan, U. S., and Bell, T. F.: Spatial structure of sprites, Geophys. Res. Lett., 25, 2123-2126, doi:10.1029/98GL01242, 1998

Price, C., Penner, J., and Prather, M.: NOx from lightning: 1. Global distribution based on lightning physics, J. Geophys. Res.-Atmos., 102, 5929-5941, doi:10.1029/96JD03504, 1997.

Radojević, V., Kelly, H. P., and Johnson, W. R.: Photodetachment of negative halogen ions, Phys. Rev. A, 35, 2117-2121, doi:10.1103/PhysRevA.35.2117, 1987.

Raizer, Y. P., Milikh, G. M., Shneider, M. N., and Novakovski, S. V.: Long streamers in the upper atmosphere above thundercloud, J. Appl. Phys. D, 31, 3255-3264, doi:10.1088/00223727/31/22/014, 1998

Ramaroson, R.: Modélisation locale, á une et trois dimensions des processus photochimiques de l'atmosphére moyenne, Ph.D. thesis, Université Paris VI, 1989.

Ramaroson, R., Pirre, M., and Cariolle, D.: A box model for on-line computations of diurnal variations in a 1-D model - Potential for application in multidimensional cases, Ann. Geophys., 10, 416428, 1992 http://www.ann-geophys.net/10/416/1992/.

Rodger, C. J., Seppälä, A., and Clilverd, M. A.: Significance of transient luminous events to neutral chemistry: Experimental measurements, Geophys. Res. Lett., 35, L07803, doi:10.1029/2008GL033221, 2008.

Sentman, D. D. and Stenbaek-Nielsen, H. C.: Chemical effects of weak electric fields in the trailing columns of sprite streamers, Plasma Sources Sci. T., 18, 034012, doi:10.1088/09630252/18/3/034012, 2009.

Sentman, D. D., Wescott, E. M., Osborne, D. L., Hampton, D. L., and Heavner, M. J.: Preliminary results from the Sprites94 Aircraft Campaign: 1. Red sprites, Geophys. Res. Lett., 22, 1205 1208, doi:10.1029/95GL00583, 1995.

Sentman, D. D., Stenbaek-Nielsen, H. C., McHarg, M. G., and Morrill, J. S.: Plasma chemistry of sprite streamers, J. Geophys. Res., 113, D11112, doi:10.1029/2007JD008941, 2008a.

Sentman, D. D., Stenbaek-Nielsen, H. C., McHarg, M. G., and Morrill, J. S.: Correction to "Plasma chemistry of sprite streamers", J. Geophys. Res., 113, D14399, doi:10.1029/2008JD010634, 2008b.

Smith, G. P. and Lee, L. C.: Photodissociation of atmospheric positive ions. II. 3500-8600Å, J. Chem. Phys., 69, 5393-5399, doi:10.1063/1.435324, 1978.

Smith, G. P., Cosby, P. C., and Moseley, J. T.: Photodissociation of atmospheric positive ions. I. 3500-6700A, J. Chem. Phys., 67, 3818-3828, doi:10.1063/1.436569, 1977.

Smith, G. P., Lee, L. C., Cosby, P. C., Peterson, J. R., and Moseley, J. T.: Photodissociation and photodetachment of molecular 
negative ions. V. Atmospheric ions from 7000 to $8400 \AA$, J. Chem. Phys., 68, 3818-3822, doi:10.1063/1.436188, 1978.

Smith, G. P., Lee, L. C., and Cosby, P. C.: Photodissociation and photodetachment of molecular negative ions. VIII. Nitrogen oxides and hydrates, 3500-8250 Å, J. Chem. Phys., 71, 4464-4470, doi:10.1063/1.438199, 1979a.

Smith, G. P., Lee, L. C., and Moseley, J. T.: Photodissociation and photodetachment of molecular negative ions. VII. Ions formed in $\mathrm{CO}_{2} / \mathrm{O}_{2} / \mathrm{H}_{2} \mathrm{O}$ mixtures, 3500-5300 $\AA$, J. Chem. Phys., 71, 40344041, doi:10.1063/1.438171, 1979b.

Stanley, M. A.: Sprites and their Parent Discharges, Ph.D. thesis, New Mexico Institude of Mining and Technology, Socorro, NM, USA, 2000.

Stanley, M., Brook, M., Krehbiel, P., and Cummer, S. A.: Detection of daytime sprites via a unique sprite ELF signature, Geophys. Res. Lett., 27, 871-874, doi:10.1029/1999GL010769, 2000.
Stenbaek-Nielsen, H. C. and McHarg, M. G.: High time-resolution sprite imaging: observations and implications, J. Appl. Phys. D, 41, 234009, doi:10.1088/0022-3727/41/23/234009,2008.

Winkler, H. and Notholt, J.: A model study of the negative chlorine ion chemistry in the Earth's mesosphere, Adv. Space Res., 51, 2342-2352, 2013.

Winkler, H., Kazeminejad, S., Sinnhuber, M., Kallenrode, M.B., and Notholt, J.: Conversion of mesospheric $\mathrm{HCl}$ into active chlorine during the solar proton event in July 2000 in the northern polar region, J. Geophys. Res., 114,D00I03, doi:10.1029/2008JD011587, 2009.

Zipf, E., Espy, P., and Boyle, C.: The excitation and collisional deactivation of metastable N(2P) atoms in auroras, J. Geophys. Res., 85, 687-694, doi:10.1029/JA085iA02p00687, 1980. 